Acta Sci. Pol. Technol. Aliment. 20(2) 2021, 213-222

pISSN 1644-0730

eISSN 1898-9594

http://dx.doi.org/10.17306/J.AFS.2021.0921

ORIGINAL PAPER

Received: 4.12.2020

Accepted: 6.03.2021

\title{
THE EFFECTS OF FOLATE AND IRON DEFICIENCY FOLLOWED BY SUPPLEMENTATION ON BLOOD MORPHOLOGY AND INFLAMMATION BIOMARKERS IN RATS
}

\author{
Anna Radziejewska ${ }^{1}$, Joanna Suliburska ${ }^{1}$, Paweł Kołodziejski², Ewelina Zuk ${ }^{1}$, \\ Agata Chmurzynska ${ }^{1 \bowtie}$
}

${ }^{1}$ Department of Human Nutrition and Dietetics, Poznań University of Life Sciences

Wojska Polskiego 31, 60-624 Poznań, Poland

2Department of Animal Physiology and Biochemistry, Poznań University of Life Sciences

Wołyńska, 60-637 Poznań, Poland

\begin{abstract}
Background. Little is known about the relation between iron and folic acid (FA) supplementation and inflammation. The aim of this study was to evaluate the effects of iron and folate deficiency and supplementation on blood morphology parameters, and to assess the role of iron and folate transporters in inflammation.

Materials and methods. A four-week period of FA and iron deficiency in Wistar rats was followed by randomization into a group fed with a diet deficient in FA and supplemented with Fe (DFE), a group fed a diet deficient in Fe and supplemented with FA (DFOL), a group fed a diet supplemented with Fe and FA (FEFOL), a group fed a diet deficient in Fe and FA (D), and a group fed a control diet (C). The blood Crp concentration and blood count were determined. The expression of SLC11A2, SLC46A1, SLC19A1, and TFR 2 proteins was assessed using the western blot method.

Results. After ten days on the experimental diets, the rats in the DFOL group had a $21 \%$ higher concentration of white blood cells (WBC) than the FEFOL group did $(p<0.05)$. We did not observe any differences between the groups in terms of C-reactive protein (Crp) concentration. We also did not find any other differences between the groups in other morphological parameters. Analysis of the correlation between blood count parameters and the expression of iron and folate transporters gave conflicting results.

Conclusion. To conclude, iron and folate supplementation may affect WBC concentration in the blood.
\end{abstract}

Keywords: iron, folate, supplementation, inflammation, transporters

\section{INTRODUCTION}

In recent years, research interest on the relation between nutrition and inflammation has been increasing. Numerous food products have recently been reported to inhibit inflammation (Ahluwalia et al., 2013), and there is increasing evidence that dietary quality and micronutrient intake may have both proinflammatory and antiinflammatory effects on the body (Kantor et al., 2013).
Inflammation is an immediate protective response of the body to cell damage, tissue injury, pathogens, or toxic agents. Prolonged and chronic low-grade inflammation can lead to the development of inflammatory diseases such as asthma, atherosclerosis, and rheumatoid arthritis (Minihane et al., 2015). Many mediators and cell products are involved in inflammatory

\agata.chmurzynska@up.poznan.pl, phone 48618466181 
reactions. Agents such as leucocytes, granulocytes, monocytes, cytokines, C-reactive protein, and others are used as biomarkers of inflammation (Germolec et al., 2018). However, there is no agreement on which of these factors is the most accurate biomarker of inflammation (Calder et al., 2011).

For young women's health, an adequate intake of iron and folate is particularly important, and these are components of many supplements for pregnant women. As a constituent of hemoglobin, iron is involved as a cofactor in many enzymatic reactions, as well as in oxygen transport and erythropoiesis (Anderson and Frazer, 2017). Both iron deficiency and iron overload have detrimental effects on health and may also promote inflammatory reactions. Iron levels in the body are thus tightly regulated by numerous mechanisms, mostly related to iron absorption, which maintain homeostasis of this trace element. Iron deficiency mimics the effects of hypoxia and may stimulate cytokine synthesis (Renassia and Peyssonnaux, 2019). On the other hand, iron overload may generate reactive oxygen species that cause cellular damage (Anderson and Shah, 2013). It has also been observed that iron status is strongly associated with many inflammatory chronic diseases, such as obesity, diabetes, and metabolic syndrome (Ford and Cogswell, 1999; Jiang et al., 2004; Vari et al., 2007). Folate, also known as vitamin $B_{9}$, is involved in many metabolic reactions and participates in purine and pyrimidine synthesis (Greenberg et al., 2011). Supplementation with folic acid, which is a synthetic form of folate, is recommended for young women, as it can prevent many birth defects such as spina bifida (Scientific opinion..., 2014). It has also been observed that folate status is associated with oxidative stress (Talari et al., 2016) and this mechanism may also affect CRP levels. However, results of previous studies have given conflicting results on whether FA can lower CRP (Asemi et al., 2016; Spoelstra-de et al., 2004). Folates may also counteract oxidative stress by lowering the level of homocysteine (Racek et al., 2005).

The absorption and transport of iron and folate are dependent on the transporters of these micronutrients, as well as on other proteins involved in their metabolism. In the duodenum, iron absorption is driven by Divalent Metal Transporter (SLC11A2), while in the liver iron transport is mediated by Transferrin Receptor 2 (TFR2). Folate absorption in the duodenum is supported by proton-coupled folate transporter (SLC46A1), whereas Reduced Folate Carrier (SLC19A1) is involved in uptake of the reduced form of folate in the liver.

The aim of this study was to evaluate the effects of iron and folate deficiency and supplementation on blood morphology parameters, as we have previously shown that the relation between iron and folate transporters and their metabolism is inconclusive. We additionally wanted to assess the role of iron and folate transporters in inflammation. We hypothesized that iron and folate supplementation may modify blood parameters and thus iron and folate transporter levels may be associated with inflammation.

\section{MATERIALS AND METHODS}

\section{Animals and diets}

The experimental procedures were conducted in compliance with international procedures for laboratory animals. All the experimental procedures were reviewed and approved by the Bioethical Commission for Animal Care and Use in Poznań, Poland (approval no. 59/2016). One hundred and fifty female Wistar rats at eight-weeks of age were purchased from Charles River Laboratories (Germany). The animals were housed in cages with a $12 \mathrm{~h}$ light-dark cycle in an environmentally controlled room at $20-22^{\circ} \mathrm{C}$ and a humidity of 55-65\%. Following the acclimatization period, the rats were randomized to one of the following groups: the control group $(\mathrm{C}, n=30$, $\mathrm{Fe}=50 \mathrm{mg} / \mathrm{kg}, \mathrm{FA}=2 \mathrm{mg} / \mathrm{kg}$ ), fed a standard animal diet (AIN-93M) or an experimental group, fed a diet deficient in iron and folic acid (D, $n=120, \mathrm{Fe}$ $=0 \mathrm{mg} / \mathrm{kg}, \mathrm{FA}=0 \mathrm{mg} / \mathrm{kg}$ ) for 28 days. In the second stage, the rats in group D were randomly assigned to one of four subgroups whose diets were respectively deficient in FA and supplemented with iron (DFE, $n=30, \mathrm{Fe}=150 \mathrm{mg} / \mathrm{kg}$ ), deficient in iron and supplemented with FA (DFOL, $n=30, \mathrm{FA}=6 \mathrm{mg} / \mathrm{kg}$ ), supplemented with both iron and FA (FEFOL, $n=30$, $\mathrm{Fe}=150 \mathrm{mg} / \mathrm{kg}, \mathrm{FA}=6 \mathrm{mg} / \mathrm{kg}$ ), and deficient in both iron and folic acid (D, $n=30, \mathrm{Fe}=0 \mathrm{mg} / \mathrm{kg}$, $\mathrm{FA}=0 \mathrm{mg} / \mathrm{kg}$ ). The supplemented diet had 3 times greater doses than in the standard diet. The rats in the control group, as before, were fed standard AIN-93M $(\mathrm{C}, n=30)$. All experimental procedures have been 
described in detail elsewhere (Radziejewska et al., 2020). All of the rats were allowed free access to water. Food intake and body mass were measured every day using an electronic scale. After 2, 10, and 21 days, the rats were sacrificed and biological samples, including the blood, liver, and duodenum, were collected.

\section{Tissue and blood sampling}

The animals were fasted overnight and sacrificed by decapitation. The liver and duodenum were frozen in liquid nitrogen immediately and stored at $-80^{\circ} \mathrm{C}$. Blood was collected using a $B D \AA$ Vacutainer ${ }^{\circledR}$ tube with SSTTM II Advance gel (serum) and BD Vacutainer EDTA Tubes (blood for morphology) and then the serums were centrifuged at $3000 \mathrm{~g}$ for $15 \mathrm{~min}$ at $4^{\circ} \mathrm{C}$. The serums were frozen and stored for further analysis at $-80^{\circ} \mathrm{C}$.

\section{Protein isolation}

The proteins were isolated from $200 \mathrm{mg}$ of duodenum and liver tissue. The samples were homogenized in an ice-cold RIPA buffer (containing $50 \mathrm{mmol}$ Tris- $\mathrm{HCl}$, pH 8.0, with $150 \mathrm{mM} \mathrm{NaCl}, 1.0 \% \mathrm{NP}-40,0.5 \%$ sodium deoxycholate, $0.1 \%$ sodium dodecyl sulfate (SDS), $10 \mathrm{mM} \mathrm{NaF}$, and $1 \mathrm{mM} \mathrm{Na}_{3} \mathrm{VO}_{4}$ ) supplemented with a protease inhibitor cocktail. Proteins were obtained by centrifugation of the homogenates at $10,000 \mathrm{~g}$ for $10 \mathrm{~min}$ at $4^{\circ} \mathrm{C}$. The concentrations of the proteins were determined using a BCA kit (Thermo Scientific, Waltham, MA, USA).

\section{Western blot analysis}

Samples containing $20 \mu \mathrm{g}$ of total protein were resolved in $4 \%$ acrylamide stacking gel and $12 \%$ resolving Tris-HCl SDS-PAGE gel for $1.5 \mathrm{~h}$ at $125 \mathrm{~V}$. The samples were subsequently blotted onto a nitrocellulose membrane (BioRad, USA). The membranes were blocked by incubation with 3\% BSA in TBST solution for 1 hour. The membranes were then incubated with primary antibodies (SLC46A1 Antibody, Aviva Systems Biology, USA; SLC11A2 Antibody, Santa Cruz Biotechnology, USA; Polyclonal rabbit anti-RFC, Alpha Diagnostics, USA, Mouse Anti-Human Transferrin Receptor, Invitrogen, USA), diluted to 1:1000 in TBST and supplemented with $1 \%$ of BSA at $4^{\circ} \mathrm{C}$ overnight. The membranes were then washed three times for 3 minutes with TBST buffer and incubated with a secondary antibody diluted to 1:5000 for $1 \mathrm{~h}$. ECL substrate (Thermo Scientific, USA) was used to visualize the signals. The bands were determined using a chemiluminescence system on a ChemiDoc MP Imaging System (BioRad, USA). The results were normalized to $\beta$-actin protein levels.

\section{Morphological parameters}

Whole-blood morphological analysis was performed in a commercial laboratory using a Sysmex XT-4000 system (Synevo). The following morphological parameters were analyzed: white blood cells (WBC), monocytes, neutrophiles, and lymphocytes.

\section{Statistical analysis}

Data are shown as group means with standard deviations. Group differences were assessed using one-way ANOVA. The Shapiro-Wilk test was used to examine the normality of the data distribution. Correlations between morphological parameters and transcript/ protein levels were determined using Spearman's rank correlation coefficients. Calculations were performed with Statistica software (StatSoft).

\section{RESULTS}

The concentrations of C-reactive protein and morphological parameters were measured after 2, 10, and 21 days of the animals being fed the experimental diets. After ten days on the experimental diets, the rats in the DFOL group had $21 \%$ higher WBC concentrations than those in the FEFOL group $(p<0.05$; Table 1$)$. We did not find any other differences between the groups in terms of the other morphological parameters.

There was a negative correlation between SLC11A2 protein level and platelet (Plt) concentration in the DFE group at the second time-point $(r=-0.76$, $p<0.05$; Table 2). In the same group, there was also a negative correlation between Plt and SLC46A1 protein concentration after ten days of supplementation $(r=-0.70, p<0.05$; Table 2$)$.

At the third time-point, the SLC46A1 protein in the DFOL group correlated negatively with the monocyte concentration ( $r=-0.73, p<0.05$; Table 3$)$. We also observed a negative correlation between the SLC19A1 protein and Crp concentrations after 10 days of supplementation in the DFOL group $(r=-0.80, p<0.05$; 
Radziejewska, A., Suliburska, J., Kołodziejski, P., Zuk, E., Chmurzynska, A. (2021). The effects of folate and iron deficiency followed by supplementation on blood morphology and inflammation biomarkers in rats. Acta Sci. Pol. Technol. Aliment., 20(2), $213-222$. http://dx.doi.org/10.17306/J.AFS.2021.0921

Table 1. Group differences in serum concentrations of C-reactive protein and morphological parameters

\begin{tabular}{|c|c|c|c|c|c|c|c|c|c|c|c|}
\hline & \multicolumn{2}{|c|}{ DFE } & \multicolumn{2}{|c|}{ DFOL } & \multicolumn{2}{|c|}{ FEFOL } & \multicolumn{2}{|c|}{ D } & \multicolumn{2}{|c|}{$\mathrm{C}$} & \multirow{2}{*}{$P$-value } \\
\hline & mean & SD & mean & SD & mean & SD & mean & SD & mean & SD & \\
\hline \multicolumn{12}{|c|}{ First time-point (day 2) } \\
\hline CRP, mg/l & 0.03 & 0.03 & 0.01 & 0.01 & 0.02 & 0.02 & 0.01 & 0.00 & 0.02 & 0.01 & NS \\
\hline WBC, g/l & 6.14 & 2.27 & 5.78 & 1.96 & 6.95 & 1.25 & 5.62 & 1.84 & 7.04 & 2.82 & NS \\
\hline Monocytes, g/1 & 0.21 & 0.12 & 0.26 & 0.11 & 0.26 & 0.10 & 0.19 & 0.07 & 0.16 & 0.12 & NS \\
\hline Neutrophil, g/l & 1.22 & 0.42 & 1.45 & 0.73 & 1.16 & 0.44 & 1.34 & 0.41 & 1.48 & 1.15 & NS \\
\hline Lymphocytes, g/l & 4.60 & 1.94 & 3.92 & 1.88 & 5.43 & 1.09 & 3.98 & 1.93 & 5.23 & 2.32 & NS \\
\hline \multicolumn{12}{|c|}{ Second time-point (day 10) } \\
\hline CRP, mg/l & 0.06 & 0.02 & 0.05 & 0.02 & 0.05 & 0.02 & 0.06 & 0.04 & 0.03 & 0.01 & NS \\
\hline WBC, g/l & $5.98^{\mathrm{a}, \mathrm{b}}$ & 1.40 & $7.09^{\mathrm{a}}$ & 1.41 & $4.23^{\mathrm{b}}$ & 1.38 & $5.63^{\mathrm{a}, \mathrm{b}}$ & 1.83 & $7.04^{\mathrm{a}, \mathrm{b}}$ & 2.80 & 0.01 \\
\hline Monocytes, g/1 & 0.14 & 0.06 & 0.21 & 0.10 & 0.19 & 0.08 & 0.17 & 0.08 & 0.13 & 0.13 & NS \\
\hline Neutrophil, g/l & 1.26 & 0.42 & 1.41 & 0.47 & 1.09 & 0.17 & 1.36 & 0.41 & 1.48 & 1.16 & NS \\
\hline Lymphocytes, g/1 & 4.54 & 1.10 & 5.34 & 1.48 & 2.89 & 1.28 & 3.94 & 1.85 & 5.22 & 2.33 & NS \\
\hline \multicolumn{12}{|c|}{ Third time-point (day 21) } \\
\hline $\mathrm{CRP}, \mathrm{mg} / 1$ & 0.09 & 0.05 & 0.08 & 0.03 & 0.08 & 0.03 & 0.06 & 0.04 & 0.07 & 0.03 & NS \\
\hline WBC, g/l & 6.11 & 1.49 & 7.00 & 1.29 & 6.00 & 1.36 & 5.63 & 1.95 & 6.26 & 1.54 & NS \\
\hline Monocytes, g/1 & 0.22 & 0.14 & 0.22 & 0.09 & 0.19 & 0.13 & 0.14 & 0.07 & 0.17 & 0.09 & NS \\
\hline Neutrophil, g/l & 1.28 & 0.43 & 1.57 & 0.50 & 1.13 & 0.38 & 1.48 & 1.18 & 1.23 & 0.19 & NS \\
\hline Lymphocytes, g/l & 4.53 & 1.54 & 5.16 & 1.04 & 4.62 & 1.19 & 3.95 & 1.39 & 4.80 & 1.42 & NS \\
\hline
\end{tabular}

$P$-values show the significance levels for the differences between dietary groups within sections.

$\mathrm{CRP}$ - C-reactive protein, WBC - white blood cells, NS - not significant.

${ }^{\mathrm{a}, \mathrm{b}}$ Mean values within a row with different superscript letters are significantly different.

Table 3). In the DFOL group, the SLC46A1 protein level was correlated negatively with the lymphocyte concentration after 21 days of supplementation $(r=-0.68, p<0.05$; Table 3$)$.

In the FEFOL group, there was another strong positive correlation between $\mathrm{RBC}$ concentration and SLC46A1 after ten days of supplementation ( $r=0.89$, $p<0.05$; Table 4 ). In the same group and at the same time-point, we also observed a positive correlation between Mchc concentration and TFR2 level $(r=0.71$, $p<0.05$; Table 4). After 10 days of supplementation, SLC11A2 protein correlated positively with WBC concentrations in group $\mathrm{D}$ at the second time-point $(r=-0.67, p<0.05$; Table 5$)$. We did not observe any correlations between WBC concentration and any protein concentrations in group $\mathrm{C}$ (Table 6).

\section{DISCUSSION}

One of the strongest environmental influencers of chronic systemic inflammation is diet (Ahluwalia et al., 2013), so we also wanted to assess the role of iron and folate levels in inflammation. For this reason, the expression of folate and iron transporters was measured in the duodenums and livers of the rats. To our knowledge, this is the first time that the expression of these transporters has been analyzed in this context. The present study provides evidence that the 
Radziejewska, A., Suliburska, J., Kołodziejski, P., Zuk, E., Chmurzynska, A. (2021). The effects of folate and iron deficiency followed by supplementation on blood morphology and inflammation biomarkers in rats. Acta Sci. Pol. Technol. Aliment., 20(2), $213-222$. http://dx.doi.org/10.17306/J.AFS.2021.0921

Table 2. Spearman's rank correlations between morphological parameters and SLC11A2, SLC46A1, SLC19A1, and TFR2 protein levels in the DFE group

\begin{tabular}{|c|c|c|c|c|c|c|c|c|c|c|c|}
\hline & Crp & WBC & $\begin{array}{c}\text { Neutro- } \\
\text { phils }\end{array}$ & $\begin{array}{l}\text { Lympho- } \\
\text { cytes }\end{array}$ & $\begin{array}{l}\text { Mono- } \\
\text { cytes }\end{array}$ & $\mathrm{RBC}$ & Htc & $\mathrm{Mcv}$ & Mch & Mche & Plt \\
\hline \multicolumn{12}{|c|}{ Second time-point (day 10) } \\
\hline SLC11A2 protein & -0.42 & 0.20 & 0.50 & -0.07 & 0.15 & 0.17 & 0.13 & 0.07 & -0.23 & -0.26 & -0.76 \\
\hline SLC46A1 protein & -0.42 & 0.32 & 0.55 & 0.07 & 0.23 & 0.27 & 0.17 & 0.13 & -0.19 & -0.37 & -0.70 \\
\hline SLC19A1 protein & 0.08 & -0.22 & 0.08 & -0.31 & -0.09 & 0.08 & -0.18 & 0.37 & 0.49 & 0.29 & -0.38 \\
\hline TFR2 protein & -0.26 & 0.38 & 0.08 & 0.50 & 0.52 & -0.19 & -0.02 & -0.21 & -0.20 & 0.22 & 0.52 \\
\hline \multicolumn{12}{|c|}{ Third time-point (day 21) } \\
\hline SLC11A2 protein & 0.10 & 0.10 & -0.62 & 0.24 & 0.02 & -0.19 & -0.20 & 0.10 & -0.02 & 0.29 & 0.05 \\
\hline SLC46A1 protein & -0.02 & 0.38 & 0.07 & 0.24 & 0.50 & 0.33 & 0.17 & 0.10 & 0.33 & 0.44 & -0.31 \\
\hline SLC19A1 protein & 0.10 & -0.37 & -0.13 & -0.15 & -0.33 & -0.15 & -0.39 & -0.53 & -0.42 & 0.38 & 0.33 \\
\hline TFR2 protein & 0.22 & -0.50 & -0.38 & -0.35 & -0.28 & -0.27 & -0.10 & 0.18 & 0.15 & 0.38 & 0.55 \\
\hline
\end{tabular}

Crp - C-reactive protein, WBC - white blood cells, RBC - red blood cells, Htc - hematocrit, Mcv - mean corpuscular volume, $\mathrm{Mch}$ - mean corpuscular hemoglobin, Mchc - mean corpuscular hemoglobin concentration, Plt - platelets.

Table 3. Spearman's rank correlations between morphological parameters and SLC11A2, SLC46A1, SLC19A1, and TFR2 protein levels in the DFOL group

\begin{tabular}{|c|c|c|c|c|c|c|c|c|c|c|c|}
\hline & Crp & WBC & $\mathrm{Neu}$ & Lym & Mono & $\mathrm{RBC}$ & Htc & $\mathrm{Mcv}$ & Mch & Mchc & Plt \\
\hline \multicolumn{12}{|c|}{ Second time-point (day 10) } \\
\hline SLC11A2 protein & -0.34 & 0.14 & 0.31 & 0.05 & 0.62 & 0.43 & 0.34 & 0.10 & 0.02 & 0.16 & -0.24 \\
\hline SLC46A1 protein & 0.24 & 0.10 & -0.21 & 0.29 & -0.05 & -0.17 & -0.65 & -0.26 & 0.07 & 0.33 & 0.00 \\
\hline SLC19A1 protein & 0.23 & -0.24 & -0.05 & -0.26 & 0.30 & 0.06 & -0.45 & 0.04 & 0.07 & 0.12 & -0.19 \\
\hline TFR2 protein & 0.17 & -0.03 & -0.07 & -0.02 & -0.59 & -0.47 & -0.29 & -0.32 & -0.50 & -0.15 & 0.08 \\
\hline \multicolumn{12}{|c|}{ Third time-point (day 21) } \\
\hline SLC11A2 protein & -0.02 & -0.33 & 0.00 & -0.28 & -0.70 & 0.08 & 0.00 & 0.13 & 0.12 & 0.33 & -0.64 \\
\hline SLC46A1 protein & 0.03 & -0.62 & 0.02 & -0.68 & -0.73 & 0.12 & 0.25 & 0.17 & 0.15 & 0.31 & -0.23 \\
\hline SLC19A1 protein & -0.80 & -0.09 & 0.01 & -0.22 & -0.49 & 0.09 & -0.36 & -0.57 & -0.67 & -0.04 & -0.20 \\
\hline TFR2 protein & -0.26 & 0.27 & 0.24 & 0.25 & 0.27 & -0.43 & -0.12 & -0.07 & -0.23 & -0.58 & 0.09 \\
\hline
\end{tabular}

Crp - C-reactive protein, WBC - white blood cells, RBC - red blood cells, Htc - hematocrit, Mcv - mean corpuscular volume, Mch - mean corpuscular hemoglobin, Mchc - mean corpuscular hemoglobin concentration, Plt - platelets. 
Radziejewska, A., Suliburska, J., Kołodziejski, P., Zuk, E., Chmurzynska, A. (2021). The effects of folate and iron deficiency followed by supplementation on blood morphology and inflammation biomarkers in rats. Acta Sci. Pol. Technol. Aliment., 20(2), $213-222$. http://dx.doi.org/10.17306/J.AFS.2021.0921

Table 4. Spearman's rank correlations between morphological parameters and SLC11A2, SLC46A1, SLC19A1, and TFR2 protein levels in the FEFOL group

\begin{tabular}{lccccccccccc}
\hline & Crp & WBC & Neu & Lym & Mono & RBC & Htc & Mcv & Mch & Mchc & Plt \\
\hline & & & & Second time-point (day 10) & & & & \\
\hline SLC11A2 protein & 0.04 & 0.60 & 0.20 & 0.70 & -0.50 & -0.22 & -0.80 & -0.60 & -0.50 & 0.31 & 0.36 \\
SLC46A1 protein & -0.36 & -0.80 & -0.60 & $-\mathbf{0 . 9 0}$ & 0.30 & $\mathbf{0 . 8 9}$ & 0.40 & 0.20 & 0.30 & -0.31 & -0.05 \\
SLC19A1 protein & 0.06 & 0.38 & -0.51 & 0.48 & -0.02 & 0.32 & 0.05 & -0.67 & 0.43 & 0.70 & -0.16 \\
TFR2 protein & -0.25 & 0.29 & -0.07 & 0.36 & 0.60 & -0.30 & 0.40 & -0.24 & 0.43 & $\mathbf{0 . 7 1}$ & 0.17 \\
\hline & & & & Third time-point (day 21) & & & & & \\
\hline SLC11A2 protein & -0.52 & 0.55 & 0.26 & 0.31 & 0.00 & 0.60 & $\mathbf{0 . 7 1}$ & 0.67 & -0.11 & -0.22 & -0.33 \\
SLC46A1 protein & -0.63 & 0.19 & 0.26 & 0.05 & -0.33 & 0.20 & 0.40 & 0.14 & -0.23 & 0.09 & 0.10 \\
SLC19A1 protein & 0.15 & -0.01 & -0.25 & 0.05 & 0.36 & 0.00 & 0.01 & -0.22 & -0.34 & -0.13 & 0.09 \\
TFR2 protein & 0.22 & 0.33 & 0.04 & 0.27 & 0.14 & 0.23 & -0.27 & -0.24 & -0.21 & 0.13 & 0.45 \\
\hline
\end{tabular}

Crp - C-reactive protein, WBC - white blood cells, Rbc - red blood cells, Htc - hematocrit, Mcv - mean corpuscular volume, Mch - mean corpuscular hemoglobin, Mchc - mean corpuscular hemoglobin concentration, Plt - platelets.

Table 5. Spearman's rank correlations between morphological parameters and SLC11A2, SLC46A1, SLC19A1, and TFR2 protein levels in the D group

\begin{tabular}{|c|c|c|c|c|c|c|c|c|c|c|c|}
\hline & Crp & WBC & $\mathrm{Neu}$ & Lym & Mono & $\mathrm{RBC}$ & Htc & $\mathrm{Mcv}$ & Mch & Mchc & Plt \\
\hline \multicolumn{12}{|c|}{ Second time-point (day 10 ) } \\
\hline SLC11A2 protein & -0.48 & -0.67 & 0.33 & -0.75 & 0.70 & -0.12 & -0.20 & -0.13 & 0.16 & 0.46 & 0.07 \\
\hline SLC46A1 protein & -0.40 & -0.57 & 0.33 & -0.73 & 0.82 & -0.13 & -0.27 & 0.08 & 0.37 & 0.54 & -0.10 \\
\hline SLC19A1 protein & 0.01 & -0.39 & 0.62 & -0.32 & -0.19 & -0.32 & -0.32 & -0.09 & -0.01 & 0.22 & 0.14 \\
\hline TFR2 protein & 0.64 & 0.09 & -0.33 & 0.37 & 0.01 & -0.10 & 0.20 & -0.25 & -0.47 & -0.22 & 0.50 \\
\hline \multicolumn{12}{|c|}{ Third time-point (day 21) } \\
\hline SLC11A2 protein & 0.55 & -0.17 & -0.23 & 0.03 & $-\mathbf{0 . 8 3}$ & -0.13 & 0.18 & 0.32 & 0.33 & 0.11 & 0.42 \\
\hline SLC46A1 protein & 0.22 & -0.13 & -0.47 & 0.23 & -0.78 & -0.17 & -0.06 & -0.06 & -0.08 & 0.05 & 0.62 \\
\hline SLC19A1 protein & -0.17 & -0.47 & 0.20 & -0.62 & 0.49 & 0.10 & -0.19 & -0.12 & -0.10 & -0.54 & -0.66 \\
\hline TFR2 protein & 0.23 & -0.42 & -0.36 & -0.07 & -0.18 & 0.02 & -0.47 & -0.35 & -0.39 & -0.47 & -0.32 \\
\hline
\end{tabular}

Crp - C-reactive protein, WBC - white blood cells, Rbc - red blood cells, Htc - hematocrit, Mcv - mean corpuscular volume, Mch - mean corpuscular hemoglobin, Mchc - mean corpuscular hemoglobin concentration, Plt - platelets. 
Radziejewska, A., Suliburska, J., Kołodziejski, P., Zuk, E., Chmurzynska, A. (2021). The effects of folate and iron deficiency followed by supplementation on blood morphology and inflammation biomarkers in rats. Acta Sci. Pol. Technol. Aliment., 20(2), $213-222$. http://dx.doi.org/10.17306/J.AFS.2021.0921

Table 6. Spearman's rank correlations between morphological parameters and SLC11A2, SLC46A1, SLC19A1, and TFR2 protein levels in the $\mathrm{C}$ group

\begin{tabular}{|c|c|c|c|c|c|c|c|c|c|c|c|}
\hline & Crp & WBC & $\mathrm{Neu}$ & Lym & Mono & $\mathrm{Rbc}$ & Htc & $\mathrm{Mcv}$ & Mch & Mchc & Plt \\
\hline \multicolumn{12}{|c|}{ Second time-point (day 10) } \\
\hline SLC11A2 protein & 0.56 & 0.36 & 0.11 & 0.69 & 0.50 & 0.26 & 0.12 & -0.12 & 0.00 & -0.20 & 0.33 \\
\hline SLC46A1 protein & 0.55 & 0.58 & 0.08 & 0.72 & 0.10 & 0.30 & 0.10 & 0.11 & 0.41 & 0.10 & 0.25 \\
\hline SLC19A1 protein & 0.33 & 0.55 & 0.04 & 0.56 & -0.13 & 0.21 & -0.07 & 0.02 & 0.24 & 0.28 & -0.37 \\
\hline TFR2 protein & 0.07 & 0.01 & -0.11 & 0.03 & 0.03 & -0.37 & -0.38 & -0.23 & -0.13 & 0.54 & -0.41 \\
\hline \multicolumn{12}{|c|}{ Third time-point (day 21) } \\
\hline SLC11A2 protein & -0.82 & -0.20 & -0.68 & -0.13 & 0.00 & 0.28 & 0.03 & -0.35 & -0.46 & -0.36 & -0.38 \\
\hline SLC46A1 protein & -0.82 & -0.75 & 0.08 & -0.70 & -0.08 & 0.20 & -0.12 & -0.30 & -0.14 & 0.08 & -0.37 \\
\hline SLC19A1 protein & 0.36 & -0.39 & 0.31 & -0.30 & -0.05 & 0.38 & 0.04 & -0.27 & 0.06 & 0.48 & 0.44 \\
\hline TFR2 protein & -0.12 & -0.53 & 0.31 & -0.42 & -0.44 & -0.41 & -0.15 & 0.21 & 0.29 & -0.12 & -0.47 \\
\hline
\end{tabular}

Crp - C-reactive protein, WBC - white blood cells, Rbc - red blood cells, Htc - hematocrit, Mcv - mean corpuscular volume, Mch - mean corpuscular hemoglobin, Mchc - mean corpuscular hemoglobin concentration, Plt - platelets.

relationship between blood count parameters and the expression of iron and folate transporters is inconclusive and further research is needed to investigate this area.

There are many indicators used as inflammatory markers. One of these is Crp, a well-established marker of systemic inflammation. As an acute-phase protein produced in the liver, it has many pathophysiologic roles in low-grade inflammation (Farhangi et al., 2013). Increased white blood cell count is also a reliable marker of inflammation and infection (Wirth et al., 2018). Low-grade inflammation can affect platelet production and activation, potentially leading to enhanced platelet aggregation (Larsen et al., 2015). On the cellular level, monocytes connect low-grade inflammation and altered lipid metabolism through production of proinflammatory cytokines (Wrigley et al., 2011).

Both iron deficiency and iron excess are deleterious to health. It has been shown that both rats fed an iron-deficient diet and those fed an iron supplemented diet showed increased oxidative stress (Walter et al., 2002). Observational studies have shown folate deficiency to be associated with higher Crp concentration in the serum of young women (González-Fernández et al., 2017). Moreover, a meta-analysis from 2018 revealed that FA supplementation can lower serum Crp concentration (Fatahi et al., 2019). A number of mechanisms have been proposed as an explanation of this. Firstly, folic acid supplementation decreases homocysteine concentration, which may result in decreased oxidative stress. Homocysteine acts as a trigger of inflammatory factors, expressed through the activation of nuclear factor kappa B (NF-kB) and poly(ADP-ribose) polymerase (PARP) (Papatheodorou and Weiss, 2007). In our previous article, we demonstrated that rats in the DFOL and FEFOL groups fed a diet supplemented with folic acid had significantly lower homocysteine concentration than the rats in group $\mathrm{D}$. However, we did not observe differences in the Crp concentration between groups at any point in time. At the second time-point, however, we observed a significantly higher WBC concentration in the DFOL group than in the FEFOL group, probably caused by the iron deficient diet. The FEFOL group had a $150 \mathrm{mg} / \mathrm{kg}$ dose of iron in the diet, compared to the DFOL group that were fed a diet that did not contain iron.

SLC11A2, also known as DMT1, is a divalent metal transporter that is involved in both iron transport and absorption. It has previously been shown that Slc11a2 
expression is increased during iron deficiency, in order to improve iron absorption (Trinder et al., 2000). In turn, iron supplementation decreases the SLC11A2 level to impair iron absorption and protect the body from iron toxicity (Shirase et al., 2010). We observed that expression of SLC11A2 in the DFE group was negatively correlated with Plt concentration. This is inconsistent with the fact that Plt concentrations reflect the iron level in the body (Kulnigg-Dabsch et al., 2012). It is likely that this is a consequence of the fact that during iron supplementation, the level of SLC11A2 decreases. We also observed a negative correlation between the SLC11A2 level and monocyte concentration in the DFOL group at the third timepoint. This may confirm the hypothesis that during iron deficiency, higher levels of SLC11A2 may lower inflammation markers.

SLC46A1 is a transporter involved in folate absorption in the duodenum. We observed that 21 days of folic acid supplementation affected the negative correlation between SLC46A1 and lymphocytes in the DFOL group, and also in the FEFOL group at the second time-point. Thakur found that folic acid deficiency and subsequent supplementation with folic acid does not affect SLC46A1 levels (Thakur et al., 2015), and this was consistent with our previous results (Radziejewska et al., 2020b). However, Henry et al. showed that both a folate deficient diet and a folate supplemented diet reduced the number of circulating lymphocytes (Henry et al., 2017). However, they used $10 \mathrm{mg} / \mathrm{kg}$ of FA in the diet, which is a higher dose of this nutrient than we used, ours being $6 \mathrm{mg} / \mathrm{kg}$ FA in the diet.

We also observed a negative correlation between SLC19A1 and Crp concentration in the DFOL group at the third time-point. We suspect that during supplementation, a higher expression of SLC19A1 accompanies the higher level of folate serum, which decreases Crp concentration (Fatahi et al., 2019).

In group $\mathrm{D}$ at the second time-point, the level of SLC11A2 protein correlated negatively with the concentration of WBCs. During iron deficiency, the expression of SLC11A2 increases; the negative correlation with WBC seen here may reflect iron and folate deficiency, which promotes oxidative stress. Also, the level of TRFR 2 protein positively correlated with Crp concentrations, which may confirm that iron deficiency promotes an increase in inflammation.
One limitation of our study is that we did not determine other inflammatory markers, such as tumor necrosis factor, interleukin 6 , interleukin 10 , or ferritin. These well-known markers are commonly used in research into the association between diet and inflammation. In the future glutathione peroxidase activity may also be investigated as a ROS scavenging enzyme.

\section{CONCLUSION}

To conclude, a diet deficient in iron and FA and subsequently supplemented with iron or FA, or both, may alter the level of WBCs, but not that of Crp or other blood count parameters. Our correlation analysis of the relationship between blood count parameters and the expression of iron and folate transporters proved inconclusive. Further research is needed to assess the effect of these transporters on blood count parameters and inflammation markers.

\section{REFERENCES}

Ahluwalia, N., Andreeva, V. A., Kesse-Guyot, E., Hercberg, S. (2013). Dietary patterns, inflammation and the metabolic syndrome. Diabetes Metab., 39,2 99-110. http:// dx.doi.org/10.1016/j.diabet.2012.08.007

Anderson, E. R., Shah, Y. M. (2013). Iron homeostasis in the liver. Compr. Phys., 3(1), 315-330. http://dx.doi. org/10.1002/cphy.c120016

Anderson, G. J., Frazer, D. M. (2017). Current understanding of iron homeostasis. Am. J. Clin. Nutr., 106(suppl. 6), 1559S-1566S. http://dx.doi.org/10.3945/ ajcn.117.155804

Asemi, Z., Vahedpoor, Z., Jamilian, M., Bahmani, F., Esmaillzadeh, A. (2016). Effects of long-term folate supplementation on metabolic status and regression of cervical intraepithelial neoplasia: A randomized, double-blind, placebo-controlled trial. Nutrition, 32(6), 681-686. https://doi.org/10.1016/j.nut.2015.12.028

Calder, P. C., Ahluwalia, N., Brouns, F., Buetler, T., Clement, K., Cunningham, K., Esposito, K., Winklhofer-Roob, B. M. (2011). Dietary factors and low-grade inflammation in relation to overweight and obesity. Brit. J. Nutr., 106(suppl. 3), 1-78. http://dx.doi.org/10.1017/ s0007114511005460

Farhangi, M. A., Keshavarz, S.-A., Eshraghian, M., Ostadrahimi, A., Saboor-Yaraghi, A.-A. (2013). White blood cell count in women: Relation to inflammatory 
biomarkers, haematological profiles, visceral adiposity, and other cardiovascular risk factors. J. Health Popul. Nutr., 31(1), 58-64. http://dx.doi.org/10.3329/jhpn. v31i1.14749

Fatahi, S., Pezeshki, M., Mousavi, S. M., Teymouri, A., Rahmani, J., Kord Varkaneh, H., Ghaedi, E. (2019). Effects of folic acid supplementation on C-reactive protein: A systematic review and meta-analysis of randomized controlled trials. Nutr. Metab. Cardiovasc. Dis., 29(5), 432-439. http://dx.doi.org/10.1016/j.numecd.2018.11.006

Ford, E. S., Cogswell, M. E. (1999). Diabetes and serum ferritin concentration among U.S. adults. Diabetes Care, 22(12), 1978-1983. http://dx.doi.org/10.2337/diacare. 22.12 .1978

Germolec, D. R., Shipkowski, K. A., Frawley, R. P., Evans, E. (2018). Markers of inflammation. In J. DeWitt, C. Rockwell, C. Bowman (Eds.), Immunotoxicity testing. Methods in molecular biology (vol. 1803, pp. 57-79). New York, NY: Humana Press. http://dx.doi. org/10.1007/978-1-4939-8549-4_5

González-Fernández, D., del Carmen Pons, E., Rueda, D., Sinisterra, O. D., Murillo, E., Scott, M. E., Koski, K. G. (2017). C-reactive protein is differentially modulated by co-existing infections, vitamin deficiencies and maternal factors in pregnant and lactating indigenous Panamanian women. Infect. Dis. Poverty, 6(1), 94. http://dx.doi. org/10.1186/s40249-017-0307-1

Greenberg, J. A., Bell, S. J., Guan, Y., Yu, Y.-H. (2011). Folic acid supplementation and pregnancy: more than just neural tube defect prevention. Rev. Obstet. Gynecol., 4(2), 52-59. http://dx.doi.org/10.18370/23094117.2017.34.57-63

Henry, C., Nemkov, T., Casás-Selves, M., Bilousova, G., Zaberezhnyy, V., Higa, K. C., ..., DeGregor, J. (2017). Folate dietary insufficiency and folic acid supplementation similarly impair metabolism and compromise hematopoiesis. Haematologica, 102(12), 1985-1994. http://dx.doi.org/10.3324/haematol.2017.171074

Huang, R. F. S., Hsu, Y.-Ch., Lin, H.-L., Yang, F. L. (2001). Folate depletion and elevated plasma homocysteine promote oxidative stress in rat livers. J. Nutr., 131(1), 33-38. http://dx.doi.org/10.1093/jn/131.1.33

Jiang, R., Manson, J. M., Meigs, J. B., Ma, J., Rifai, N., Hu, F. B. (2004). Body iron stores in relation to risk of type 2 diabetes in apparently healthy women. JAMA, 291(6), 711-717. http://dx.doi.org/10.1001/jama.291.6.711

Kantor, E. D., Lampe, J. W., Kratz, M., White, E. (2013). Lifestyle factors and inflammation: associations by body mass index. PLoS ONE, 8(7). http://dx.doi.org/10.1371/ journal.pone.0067833

Kulnigg-Dabsch, S., Evstatiev, R., Dejaco, C., Gasche, Ch. (2012). Effect of iron therapy on platelet counts in patients with inflammatory bowel disease-associated anemia. PLoS ONE, 7(4). http://dx.doi.org/10.1371/journal. pone. 0034520

Larsen, S. B., Lerkevang Grove, E., Würtz, M., Neergaard-Petersen, S., Hvas, A.-M., Kristensen, S. D. (2015). The influence of low-grade inflammation on platelets in patients with stable coronary artery disease. Thromb. Haemost., 114(3), 519-529. http://dx.doi.org/10.1160/ TH14-12-1007

Minihane, A. M., Vinoy, S., Russell, W., Baka, A., Roche, H., Tuohy, K., ..., Calder, P. (2015). Low-grade inflammation, diet composition and health: Current research evidence and its translation. Brit. J. Nutr., 999-1012. http://dx.doi.org/10.1017/S0007114515002093

Papatheodorou, L., Weiss, N. (2007). Vascular oxidant stress and inflammation in hyperhomocysteinemia. Antioxid. Redox Sign., 9, 11, 1941-1958. http://dx.doi. org/10.1089/ars.2007.1750

Radziejewska, A., Suliburska, J., Kołodziejski, P., Chmurzynska, A. (2020). Simultaneous supplementation with iron and folic acid can affect Slc11a2 and Slc46a1 transcription and metabolite concentrations in rats. British J. Nutr., 123(3), 264-272. https://doi.org/10.1017/ S0007114519002721

Racek, J., Rusnáková, H., Trefil, L., Siala, K. (2005). The influence of folate and antioxidants on homocysteine levels and oxidative stress in patients with hyperlipidemia and hyperhomocysteinemia. Physiol. Res., 54(1), 87-95.

Renassia, C., Peyssonnaux, C. (2019). New insights into the links between hypoxia and iron homeostasis. Curr. Opin. Hematol., 26, 3, 125-130. http://dx.doi.org/10.1097/ MOH.0000000000000494

Scientific opinion on dietary reference values for folate (2014). EFSA J., 12(11). http://dx.doi.org/10.2903/j. efsa.2014.3893

Spoelstra-de, M. A., Brouwer, C. B., Terheggen, F., Bollen, J. M., Stehouwer, C. D. A., Smulders, Y. M. (2004). No effect of folic acid on markers of endothelial dysfunction or inflammation in patients with type 2 diabetes mellitus and mild hyperhomocysteinaemia. Neth. J. Med., 62(7), 246-253.

Shirase, T., Mori, K., Okazaki, Y., Itoh, K., Yamamoto, M., Tabuchi, M., ..., Toyokuni, S. (2010) Suppression of SLC11A2 expression is essential to maintain duodenal integrity during dietary iron overload. Am. J. 
Pathol., 177(2), 677-685. http://dx.doi.org/10.2353/ajpath.2010.090823

Talari, H. R., Rafiee, M., Farrokhian, A., Raygan, F., Bahmani, F., Darooghegi Mofrad, M., ..., Asemi, Z. (2016). The effects of folate supplementation on carotid intimamedia thickness and metabolic status in patients with metabolic syndrome. Ann. Nutr. Metab., 69(1), 41-50. http://dx.doi.org/10.1159/000448295

Thakur, S., Rahata, B., Hamid, A., Ahmad Najar, R., Kaur, J. (2015). Identification of regulatory mechanisms of intestinal folate transport in condition of folate deficiency. J. Nutr. Biochem., 26(10), 1084-1094. http://dx.doi. org/10.1016/j.jnutbio.2015.05.002

Trinder, D., Oatesa, P. S., Thomasa, C., Sadleirb, J., Morgan, E. H. (2000). Localisation of divalent metal transporter 1 (DMT1) to the microvillus membrane of rat duodenal enterocytes in iron deficiency, but to hepatocytes in iron overload. Gut, 46(2), 270-276. http://dx.doi. org/10.1136/GUT.46.2.270

Vari, I. S., Balkau, B., Kettaneh, A., André, P., Tichet, J., Fumeron, F., ..., Ducimetière, P. (2007). Ferritin and transferrin are associated with metabolic syndrome abnormalities and their change over time in a general population: Data from an epidemiological study on the insulin resistance syndrome (DESIR). Diabetes Care, 30(7), 1795-1801. http://dx.doi.org/10.2337/dc06-2312 Walter, P. B., Knutson, M. D., Paler-Martinez, A., Lee, S., Xu, Y., Viteri, F. E., Ames, B. E. (2002). Iron deficiency and iron excess damage mitochondria and mitochondrial DNA in rats. Proc. Nat. Acad. Sci. USA, 99(4), 22642269. http://dx.doi.org/10.1073/pnas.261708798

Wirth, M. D., Sevoyan, M., Hofseth, L., Shivappa, N., Hurley, T. G., Hébert, J. R. (2018). The Dietary Inflammatory Index is associated with elevated white blood cell counts in the National Health and Nutrition Examination Survey. Brain Behav. Immun., 69, 296-303. http:// dx.doi.org/10.1016/j.bbi.2017.12.003

Wrigley, B. J., Lip, G. Y. H., Shantsila, E. (2011). The role of monocytes and inflammation in the pathophysiology of heart failure. Eur. J. Heart Fail., 1161-1171. http:// dx.doi.org/10.1093/eurjhf/hfr122 